\title{
SELF-INCOMPATIBILITY SYSTEMS IN ANGIOSPERMS III. CRUCIFERAE
}

\author{
A. J. BATEMAN \\ John Innes Horticultural Institution, Bayfordbury, Hertford, Herts. \\ (now British Empire Cancer Campaign Fellow, at Cytogenetics Laboratory,
} Christie Hospital, Manchester, 20)

\section{INTRODUCTION}

Received 8.vii .54

THE demonstration that self-incompatibility in Iberis amara is determined by a multiple-allelic system with sporophytic determination of both style and pollen, and independence, dominance and mutual weakening (Bateman, 1954) naturally raises the question whether similar systems operate in the many other self-incompatible Cruciferous species. Several of these have been studied previously though the interpretations have not generally been in accord with my own conclusions in Iberis.

It therefore seemed desirable to re-examine the data on these other species to see whether alternative interpretations are possible which would bring them into line with the Iberis results.

\section{CARDAMINE PRATENSIS}

This species is of special historical interest because it was the first homomorphic species to be the object of a genetic study (Correns, 1912). The progeny of two plants intercrossed fell into four classes of equal size : compatible with both parents, compatible with the first parent, compatible with the second parent, and compatible with neither (see fig. I). Correns' hypothesis assumed sporophytic control of pollen and style with dominance and independence. His parental genotypes were taken to be $\mathbf{B b}$ and $\mathbf{G g}$ and the progeny: $\mathbf{B G}$ (incompatible with both parents), $\mathrm{Bg}$ (incompatible with $\mathrm{Bb}$ only), bG (incompatible with $\mathrm{Gg}$ only), and bg (compatible with both parents). Thus the big letters were dominant over the little letters but were independent of one another. Correns was not completely satisfied with his hypothesis and did not press it very hard. Indeed, it broke down when he intercrossed plants from the four sib classes, for, as shown in the figure, these four classes all appeared to be heterogeneous. It may be pointed out that, however heterogeneous a population may be, one can never distinguish more than four classes, if they are recognised only by two alternative reactions in two tests (i.e. as compatible or incompatible with two tester plants, the parents).

Fig. I summarises Correns' results, showing firstly the reaction when the sibs were tested with their parents' pollen (the basis of the classification into mating groups), and secondly, the results on intercrossing. While there is in fact a correlation between expectation and observation (out of 664 pollinations 526 agreed with expectation and 
$13^{8}$ disagreed) the discrepancy is too great for one to accept Correns' explanation unmodified. Neither he, Beatus (1934), nor myself have succeeded, however, in producing a completely satisfactory modification of the original hypothesis.
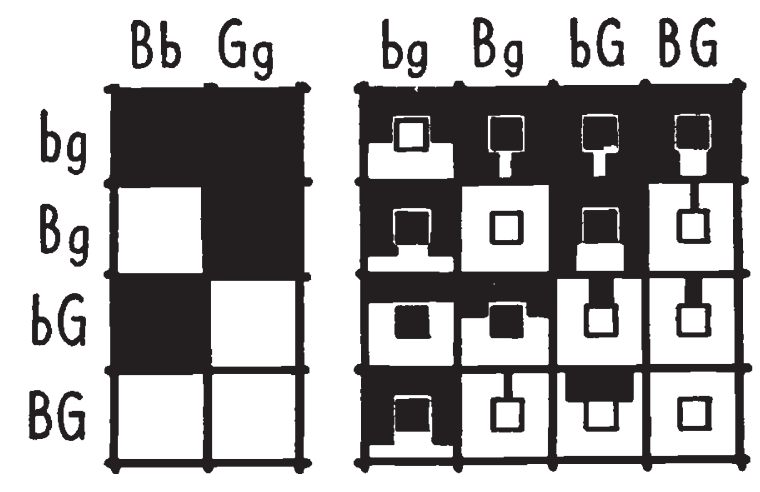

Frg. 1.-Diagrammatic representation of Correns' results with Cardamine pratensis. Columns, plants tested by pollen : rows, plants tested by style. Black, compatible : white, incompatible. Plants are represented by their presumed genotypes. $\mathrm{Bb}$ and $\mathrm{Gg}$ are the parents; $\mathbf{b g}, \mathbf{B g}, \mathrm{bG}$ and $\mathbf{B G}$ are the offspring, classified into four groups according to their compatibility with their parents' pollen (left-hand block). The right-hand block shows : smaller squares, the expected results on intercrossing sibs ; and larger squares, the results obtained. The relative frequencies of compatible and incompatible pollinations are shown by the relative areas of black and white in each square.

The acceptance of Correns' hypothesis by geneticists generally was further handicapped by the confusion in his mind between recessivity and inactivity, so that there was much discussion on how the bg genotype could be self-sterile. This would seem to be a product of the "presence-and-absence" theory of dominance.

Then came the analysis of Nicotiana by East and Mangelsdorf (1925) which was soon shown to apply to many species, and overshadowed Correns' work. Indeed it came to be accepted as the only system of homomorphic incompatibility.

One further attempt to confirm Correns' results in Cardamine was made by Beatus (1934) but although he tried to incorporate polyploid inheritance into his analysis the amount of pseudo-compatibility was too high to allow of any definite conclusions.

In the meantime, Lawrence (1930) showed that the behaviour of Correns' four classes on backcrossing to the parents (though not the crosses between sibs) could be explained on East's hypothesis by assuming tetraploidy and an unexpectedly high concentration of $S$-alleles (the parents being $S_{1} S_{I} Z_{1} Z_{2}$ and $S_{3} S_{3} Z_{3} Z_{4}$ ). Thenceforth Correns' own hypothesis was disregarded.

However, Cardamine pratensis is particularly unsuitable material for a critical analysis since there are two common races in Northern Europe, one with $2 n=30$ (a secondary tetraploid from $x=8$ ) and the other $2 n=56$ (a secondary octoploid). The octoploid is the 
more widespread and it is very probable that it was this form with which Correns dealt. A cross between plants with no common allele would then produce a family with 64 different genotypes and a maximum of 64 mating groups. It is not surprising therefore that Correns' four initial groups appeared heterogeneous on further testing! One can, however, conclude that the general nature of Correns' results are in accord with sporophytic control of the pollen, as he first postulated. This applies in particular to the incompatibility between parent and progeny and the high degree of crossincompatibility between sibs (368 out of 664 pollinations).

\section{CAPSELLA}

This genus has one self-incompatible species, $C$. grandiflora, which was the subject of intensive study by Riley (1932, 1936). It has since been regularly cited as an anomalous species, falling between heteromorphic di- or tri-polar incompatibility (Primula, Lythrum) and homomorphic multi-polar incompatibility (Nicotiana, Trifolium): (see Bateman, I952). The first has sporophytic control of the pollen, the second, gametophytic.
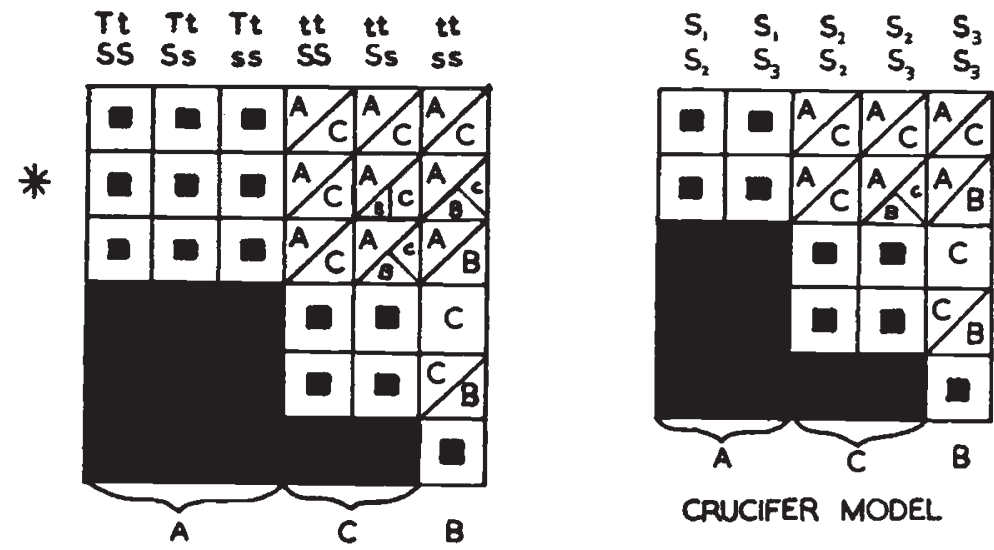

CRUCIFER MODEL

\section{LYTHRUM MODEL}

FIG. 2.-A comparison of the genetic models of incompatibility in Capsella grandiflora as proposed by Riley (Lythrum model) and myself (Crucifer model). A, B and C are the three mating groups. The proposed genotypes are shown at the head of the columns (pollen parent). The same genotypes in the same order are represented in the rows (seed parents). Dotted squares, incompatible pollinations : solid squares and those with letters entered, compatible pollinations. The size of the compartments allotted to each letter represent the proportions of those mating groups to be expected in the progeny. The genotype TtSs, shown by an asterisk, in the Lythrum model, has no counterpart in the Crucifer model. T-t, S-s are Riley's own gene symbols.

Riley established beyond doubt that the Capsella system involved sporophytic control of both pollen and style, with dominance. This (apart from Correns' neglected work) was sufficiently novel at the 
time, and Riley sought for already familiar systems which might fit his data. These he found in the tristylic Lythrum and Oxalis. To account for the presence of only three mating groups, two loci were invoked, each with two alleles, showing dominance and epistasy. Riley's hypothesis differed from Lythrum only in morphology, since Capsella was homomorphic.

In view of what we now know of other crucifers it appears opportune to re-examine Riley's evidence to see whether alternative explanations would fit.

As shown in the first paper of this series (1952) the three mating groups of trimorphic species due to two loci with two alleles at each, can be closely simulated by a single locus with three alleles in a dominance series $\mathbf{S} \mathbf{r}>\mathbf{S}_{2}>\mathbf{S} 3$, common to both sexes.

Fig. 2 compares the two hypotheses. Riley's $\mathbf{T}$ is epistatic to $\mathbf{S}-\mathbf{S}$ so that all $\mathbf{T}$-carrying plants are incompatible and $\mathbf{T} \mathbf{T}$ plants cannot arise from compatible matings. Similarly SrSr plants are not present in my model. In both models there are only three phenotypic mating groups which have been called (following Riley's notation) $A, B$ and $C$, but in Riley's model there are six genotypes, in mine only five. Each of my five genotypes behaves exactly the same as one of Riley's, both in compatibilities and in the groups produced from compatible matings. But the sixth genotype in Riley's model, the double heterozygote, Tt.Ss has no counterpart in mine. It behaves as the exact intermediate between Tt.SS and Tt.ss and its most distinctive feature is that when crossed to group $B$, the bottom recessive, it produces a 3 -group family $(2 A:$ I $C:$ I $B)$. The most critical test for deciding between the two models would therefore be the presence of a 3-group family in crosses between groups $A$ and $B$. One such family, and one only, was obtained : family 3342 in table I of the r936 paper. The observed frequencies were, however, I $A: 9 C:$ 1o $B$, when the expectation was $10 A:{ }_{5} C: 5^{B}$. $\chi^{2}$ for deviation from expectation is 16.3 for 2 degrees of freedom ( $P=$ $<$ o. OoI). The most likely explanation therefore is that the family was of type I $C:$ I $B$ with a single $A$ contaminant. While one of the parents of this family was a known $B$, the other was only inferred to be $A$ because of the presence of $A$ in the family. It seems likely that it was in fact a $C$.

Every other of the 49 families analysed by Riley would give the same expectations in either model. By analogy with Iberis and Cardamine it would appear most likely, therefore, that Capsella also has one locus with at least three alleles showing dominance. Riley himself recognised that since his material was inbred the presence of only three mating groups did not imply that the whole species was restricted to three groups. If any further groups did arise, the Cruciferous scheme could accommodate them easily whereas the Lythrum scheme could not. 


\section{BRASSICA}

Kakizaki's paper (1930) on self-incompatibility in $B$. oleracea is constantly referred to in discussions on the subject. The elaborateness of the hypothesis, evolved to explain results which have not since been confirmed, is enough to make one doubt its validity. Kakizaki's experiments were largely concerned with self-fertility which in general is quite rare in cabbages (though the author understands from F. R. Horne, Director of the National Institute of Agricultural Botany, that it is very common in cauliflower). A recent account by Odland and Noll (1950) stated that of rooo plants of Pennsylvania State Ballhead, only four were pseudo-compatible and none fully selfcompatible. These authors also quote four earlier papers by U.S. workers to the same effect. So Kakizaki's sympathetic $\mathbf{T}$ factors (promoting self-fertility ; no relation to Riley's factor with the same symbol) could not in any case be of great importance to the species.

Ten plants were selected from each of two cabbage varieties and studied separately. In each sample Kakizaki concluded that there were the same three oppositional alleles (SI, $\mathrm{S}_{2}, \mathrm{~S}_{3}$ ) and the same two sympathetic alleles (TI, T2) (there was no cross-testing). Plants heterozygous for their S-alleles were self-sterile unless they were at the same time homozygous for a $\mathrm{T}$-allele which was then epistatic (in the style) to the $\mathrm{S}$-allele. The $\mathrm{T}$-alleles promoted the growth of pollen only in styles homozygous for the same T-allele. Plants homozygous for an S-allele were always self-sterile. Both $\mathbf{S}$ and $\mathbf{T}$ acted at the gametophytic level in the pollen.

Thus we have :

Double heterozygotes; Si S2 TI T2 self-sterile.

Homozygotes for $T$ only; SI S2 TI TI self-fertile.

Homozygotes for S ; $\left(\begin{array}{llll}S_{2} & S_{2} & T_{1} & T_{2} \\ S_{2} & S_{2} & T_{I} & T_{1}\end{array}\right)$ self-sterile.

Such a system certainly agreed with the results, which were :

(a) High cross-incompatibility between unrelated plants.

(b) Different reactions of two cross-incompatible plants with a third plant.

(c) Frequent reciprocal differences in compatibility.

(d) Self-fertility.

(e) Incompatibility of some self-fertile plants with some selfsterile plants.

$(f)$ Presence of self-sterile plants in progeny of self-fertiles.

$(g)$ Presence of self-fertile plants in progeny of self-steriles.

(h) Cross-incompatibility of two self-fertile plants.

Now Kakizaki never presented proof of gametophytic control of the pollen. He merely followed East in assuming it. From our present knowledge of the Cruciferae it would seem likely that the pollen was 
in fact sporophytically controlled. In which case the results can be readily explained, without need of sympathetic factors. Results $(a)$, $(b)$ and $(c)$ are characteristic of sporophytic control with dominance and independence. Results $(d),(e),(f)$ and $(g)$ have already been experienced in Iberis amara (Bateman, 1954) where they appeared
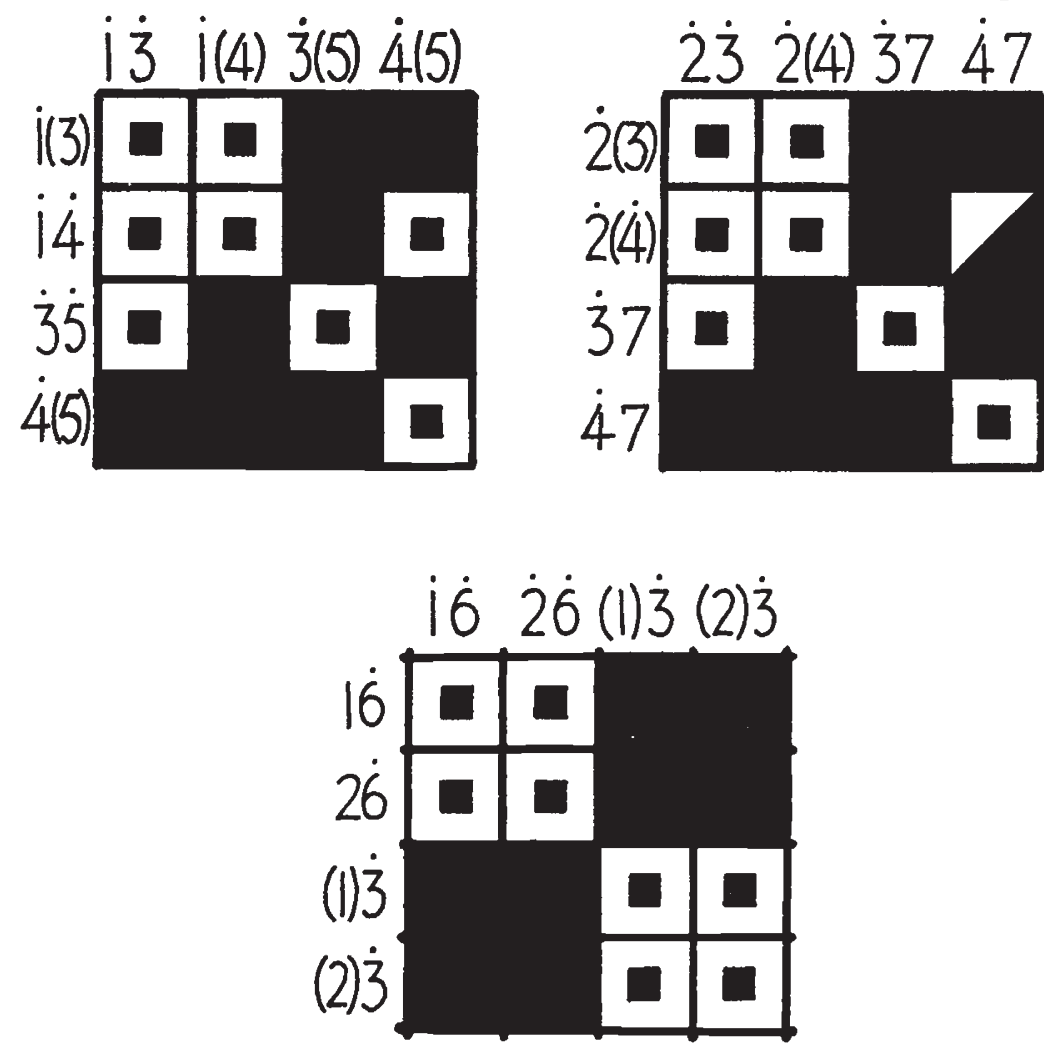

F1G. 3.-Compatibility relationships found in three typical families of Iberis amara (Bateman, 1954). Dotted squares, incompatible : solid squares, compatible : half-filled squares, partially compatible. The numbers represent the $\mathbf{S}$-alleles $\left(\mathbf{S}_{\mathbf{r}}-\mathbf{S}_{7}\right)$ with their presumed activities indicated as follows :
i active
(4) inactive
(4) partially active
7 activity unknown

The alleles of the third family are not the same as the alleles with the same numbers in the other families.

to be due to an allele $\mathbf{S}_{f}$ which was recessive to some active $\mathbf{S}$-alleles and dominant to others. Alternatively there might be a weakening of the reaction in plants heterozygous for particular S-alleles which interacted in a manner envisaged in the first paper of this series.

Point $(h)$ does present a difficulty. On Kakizaki's interpretation it arose on crossing self-fertiles of the constitutions $S_{r} S_{3} \operatorname{Tr}$ Tr and $\mathrm{Sr}_{\mathbf{1}} \mathrm{S}_{3} \mathrm{~T}_{2} \mathrm{~T}_{2}$. In the actual data, however, only a single pair of plants was involved and some seed was obtained in the reciprocal crosses though not as much as on selfing. But as no emasculations were made 
and Brassica is automatically self-pollinating, seed yields consistently less than those obtainable on selfing should be impossible. The low seed yields probably arose from causes other than incompatibility.

Summarising, the assumption of sporophytic control permits an adequate explanation of all Kakizaki's results with one dubious exception. Besides being unnecessarily complicated the $T$-factors have the additional disadvantage that if they were present throughout the species, self-fertility would be much more frequent than it is generally found to be.

Before discovering the suitability of Iberis amara for incompatibility studies I had been working with two forms of Brassica campestris; one turnip, the other an annual form, and with radish (Raphanus sativus). None of them were very suitable material for critical work because of the large amount of pseudo-compatibility. After vain attempts to fit them to a Nicotiana type scheme the data were put on one side.

Re-examination of the data in the light of the Iberis work demonstrates that they do fit into what we can now recognise as the Gruciferous type. [Correns' distinction between "Cruciferen-Typus" and "Personaten-Typus" (1928) seems justified after all in spite of the rather weak grounds on which it was originally based. We now see the terms as too narrow since the Cruciferen-Typus includes the Compositae at least, and the Personaten-Typus includes the Rosaceae and Leguminosae.]

Fig. 3 shows typical compatibility patterns between the four genotypes found in each of three sample families encountered in Iberis (Bateman, I954) with the interpretation of the gene actions there proposed.

In the turnip, families produced by crosses between plants within the variety Red-top Milan showed cross-incompatibility of about 50 per cent. The larger families seemed to fall into two or three mating groups with some cross-incompatibility between groups and sometimes reciprocal differences.

The data in an annual form of $B$. campestris, grown in India as "Toria," was my most extensive prior to the investigation of Iberis. Since one could not be sure of the compatibility of pollinations until some weeks had passed it was necessary to plan all pollinations in advance. Short of making all possible pollinations one was bound to omit some critical tests. Reciprocal families tended to give the same mating patterns but unfortunately they were not tested against each other.

Three parent plants were intercrossed in all possible ways to give six families in 3 pairs of reciprocals. The mating pattern of each is shown in fig. 4 with the interpretations in terms of the action of the S-alleles on the assumption that the parent plants were Sr S4, S2 S3 and $\mathrm{S}_{5} \mathrm{~S} 6$.

My own experience with cultivated radish had indicated a high 


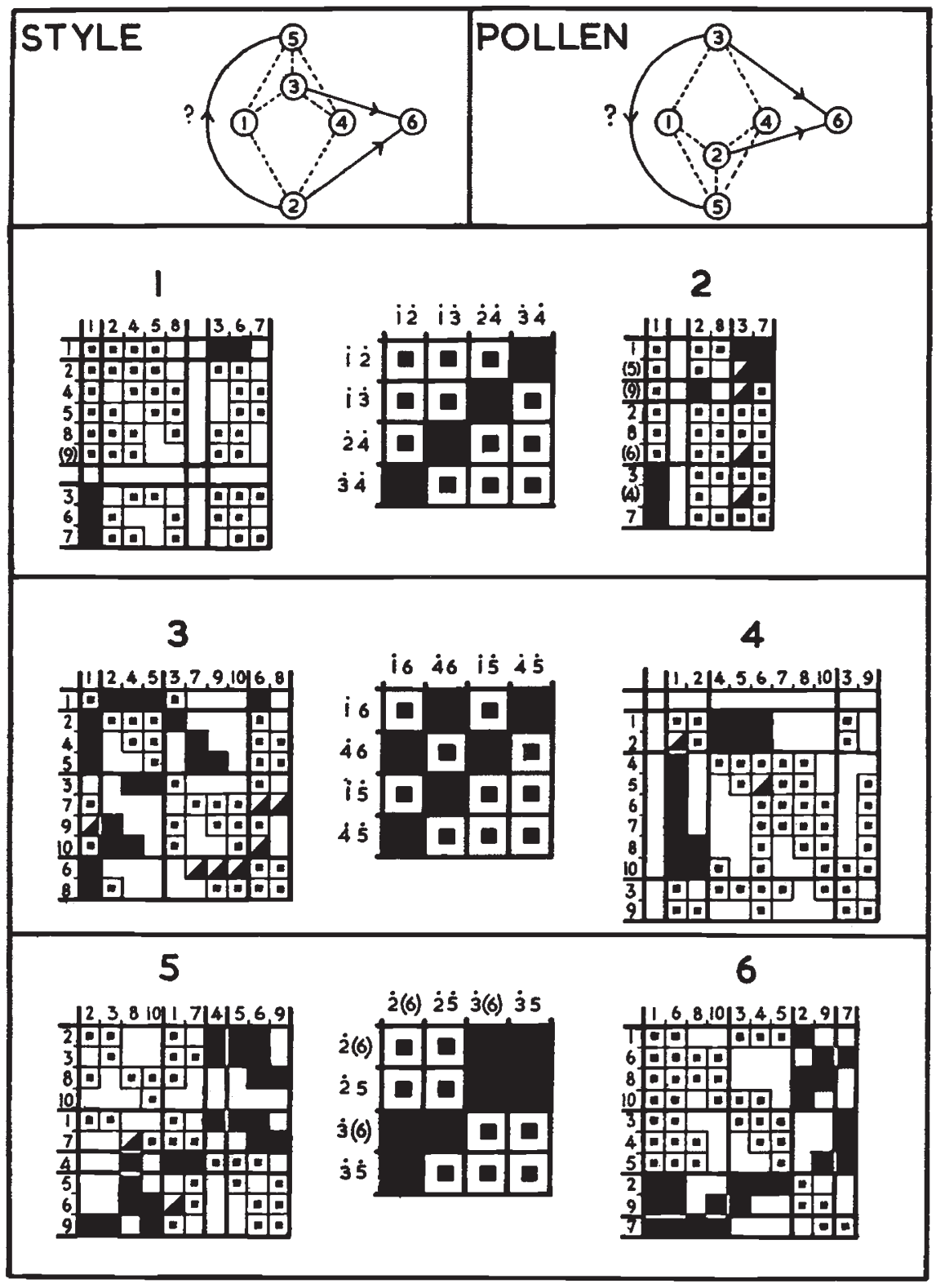

Frg. 4.--Incompatibility in Brassica campestris. I and 2, 3 and 4,5 and 6, are pairs of reciprocal families produced by making all possible crosses between 3 plants. Symbols as in fig. 3. Pollinations not made are left blank. At left and right are the pollinations between individual sibs. Plant numbers in parenthesis are those of male-steriles which could only be tested one way. Down the centre is the interpretation of the results in terms of gene action. The interaction of the genes is shown at the top. Each allele is shown as a numbered circle. Dotted lines denote independence of action; entire lines, dominance in the direction of the arrow. 
degree of cross-incompatibility between sibs (approximately $5^{\circ}$ per cent.). Mr A. Gavin Brown, however, at the John Innes Institution made an extensive series of pollinations in 1944 and 1945 which he was unable to interpret at the time and which he has kindly allowed me to study. Viewed, now, as examples of sporophytic pollen control they are readily comprehensible. I have his permission to cite one family as an example (fig. 5).

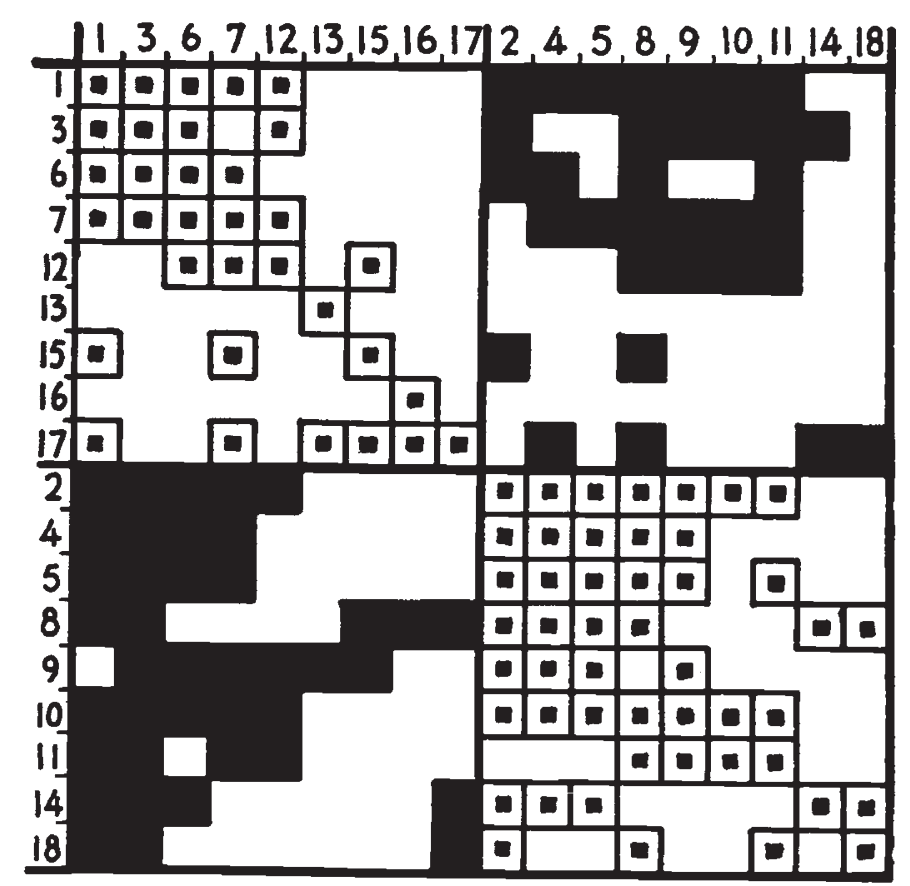

Fig. 5.-Incompatibility in Raphanus sativus. Progeny of a cross between single plants of two varieties, Scarlet Globe and French Breakfast. Symbols as in fig. 4 .

The family was produced by a cross between two plants from distinct varieties, Scarlet Globe and French Breakfast. Unless the total number of S-alleles in the species is very small it would be unlikely that the parents should have a common allele. However, as the figure shows, this large family fell into only two mating groups which were reciprocally cross-compatible ( $c f$. fig. 3 ).

Further evidence that sporophytic control of the pollen reaction is widespread in the Cruciferae was met with in a survey of the family which is discussed in detail later. Most of the samples were obtained as seed from botanic gardens where each species is usually maintained by few individuals. Amongst those samples which proved to be selfincompatible there was often a very high degree of cross-incompatibility. Indeed in some samples all five plants grown were cross-incompatible. This is circumstantial evidence of widespread sporophytic control. 


\section{TIME OF INHIBITION}

According to the literature, Brassica pekinensis (Stout, I93 I), Capsella grandiflora (Riley, 1936), B. oleracea (Sears, 1937), Raphanus sativus (Lewis, unpub.) and Iberis amara (Bateman, 1954) all show a very early inhibition of incompatible pollen. The grains barely germinate and the short, often twisted, tubes either do not penetrate the stigmatic surface at all or penetrate only a few times the diameter of the grain so that the pollen grains never empty. Not only does this similarity of behaviour suggest a common type of incompatibility system but it indicates the mechanism by which sporophytic control of the gametophytic (pollen) generation could be attained.

Sporophytic control must be determined before meiosis and persists even when the gametophyte is independent. It might be inferred, therefore, that the incompatibility resides in a persistent structure laid down at an early stage. The pollen grain wall is laid down from the cytoplasm of the pollen mother cell. If the substance responsible for the incompatibility reaction were in the wall, one can readily see that it could manifest itself immediately the pollen grain came into contact with an incompatible stigma and this would produce very early inhibition. In contrast, the determinants in gametophytic control (as in Nicotiana) cannot begin to operate until the completion of meiosis, and their effect would not appear until the gametophyte had developed to a certain stage.

In general then one would expect sporophytically controlled incompatibilities to show an earlier inhibition of incompatible pollen. It is of interest therefore that, in the Compositae, Crepis, Parthenium and Cosmos show such an early inhibition of self pollen, that it has been used as the readiest test for incompatibility by Hughes and Babcock (1950), Gerstel and Riner (1950) and Crowe (1954) in work which has demonstrated sporophytic control in that family also.

\section{THE EFFECTS OF POLYPLOIDY}

Polyploidy and especially autopolyploidy has often been associated with self-fertility in species hitherto self-sterile (see table in Lewis, 1949). As a result of his work with tetraploid Oenothera organensis (1947) Lewis concluded that this self-fertility was due to the interaction of incompatibility genes in heterogenic diploid pollen, when there had been no previous selection for their ability to work efficiently in pairs on the male side. Such an argument does not apply, of course, where there is sporophytic pollen determination, and in Crucifers, therefore, polyploidy should not be associated with self-fertility (see data of Howard, 1942).

There is an apparent exception to this rule in that in the genus Brassica, whilst the diploid species oleracea, campestris and nigra are self-sterile, their allotetraploid derivatives, napus, juncea and carnata, are all self-fertile. 
But Mizushima (1950) reports that many artificially produced allotetraploids in the Brassiceae (including $B$. carinata and $B$. juncea) are self-sterile though with good pollen and fertile in crosses with sibs or related species. The self-fertility of naturally occurring allotetraploids must therefore be secondary. Possibly the incompatibility reaction is lost as superfluous in a species which has a new way of maintaining hybridity.

\section{DISTRIBUTION OF SELF-INCOMPATIBILITY WITHIN THE FAMILY}

There is no protandry, no protogyny and no dioecy in Crucifers. In most species, anthers and stigma are so placed that self-pollination is automatic, though there are exceptions (all those I have encountered have been self-fertile). Apomixis is only known in one species, the polymorphic Arabis Holboellii, comprising races with $2 x, 3 x, 4^{x}$ and $6 x$ chromosomes, in which Böcher (195I) has shown that triploids and some diploids are pseudogamous. Apart from these apomicts it is doubtful whether any species of Crucifer is totally inbreeding, for the nectaries are always well-developed and actively secrete nectar. However small and insignificant the flowers may be, their nectaries indicate that their function is to attract insects. Furthermore, in this family, the phylogeny of which has been a big problem to the systematists, the considerable diversity in nectary structure has been given special weight in determining the relationships of the genera. According to Stebbins (I95I) this diversity is itself evidence of the adaptive importance of the Cruciferan nectar apparatus.

The three main factors determining the breeding system of the Cruciferae seem to be :

nectary arrangement, which will determine the route of approach of the pollinator and, to some extent, the species of pollinator ; size of flower, which by increasing the attractiveness to pollinators will increase the amount of outbreeding; and self-incompatibility.

This last will be the most important. From my own observations it is strongly correlated with the second. The self-sterile species generally have the most conspicuous flowers, conspicuousness being achieved either by increased size, bright colouring or special arrangements in the inflorescence, especially pseudo-umbels (as in Lobularia maritima and Iberis amara).

A survey of the distribution of self-incompatibility in the Cruciferae will be expected to throw light on its evolutionary importance.

The data of table I were based, except as shown in footnotes, on material grown from seed (usually from botanic gardens). Five plants were tested in each sample. If they all set seed readily in an insect-proof house they were at once classed as self-fertile and selfpollinating. If they did not set seed freely under those conditions each was selfed by hand and crossed to the adjoining plant. If both 


\section{TABLE I}

Distribution of self-incompatible species in the Cruciferae

(classification according to Schulz)

$\mathrm{SS}=$ self-sterile $: \mathrm{SF}=$ self-fertile

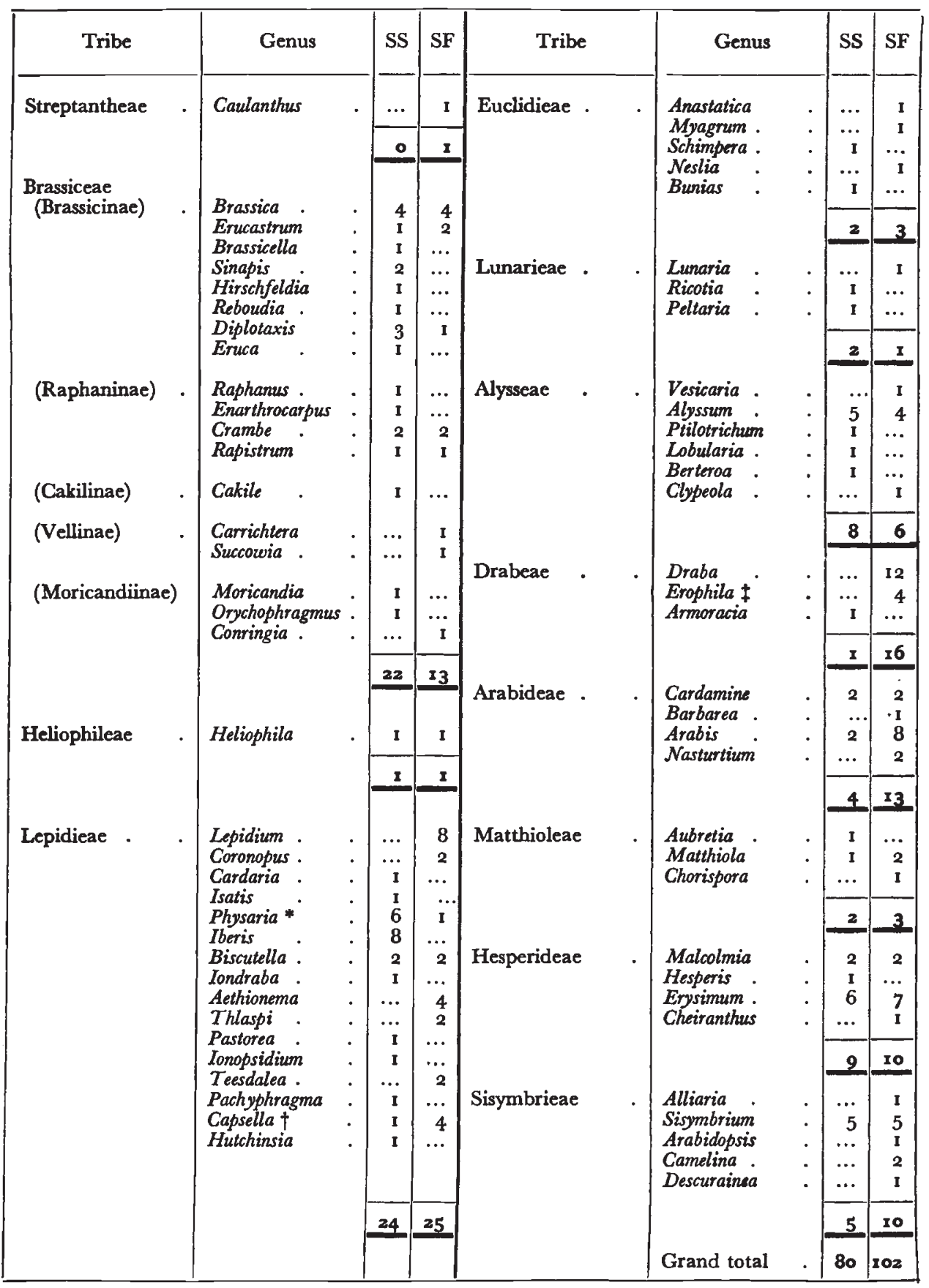

* Brewbaker (personal communication). 
types of hand pollination produced abundant seed the species was considered self-fertile but not self-pollinating. If only the crosspollination gave a full set the species was considered self-sterile. In this way many species which set appreciable amounts of seed on selfing were classified as self-sterile because cross-pollination produced a more complete set. Owing to cross-incompatibility, often only a proportion of the cross-pollinations produced full sets. Sometimes no full sets were obtained. In that case, if the plant looked healthy and the pollen was good it was classified as self-sterile. Where the five plants included both self-fertile and self-sterile individuals the species was regarded as self-sterile. Under this test, species in which the incompatibility reaction merely slowed down self pollen tubes without reducing seed setting would be classified as self-fertile though under open-pollination they might be effectively self-sterile.

The authenticity of the generic name was always checked, and usually the specific name also. Forms which were similar enough to appear to be the same species were counted as single species in the table. The total of $\mathrm{I}_{2}$ species may therefore be an underestimate. The alternatives to this treatment would have involved extensive taxonomic studies, or if every specific name had been accepted, inflated figures which would have given an exaggerated importance to the survey.

Of 182 species distributed over 12 tribes (classification according to O. E. Schulz) 80 were self-sterile and 102 self-fertile. This need not represent the relative frequencies of the two kinds in the entire family, for as self-fertile species are more readily maintained in botanic gardens they might tend to be over-represented. In any case we are not so concerned with overall frequencies as with the distribution among the tribes and genera. Of the eleven tribes sampled, the only one containing no self-sterile species is the Streptantheae, of which only a single species of Caulanthus was tested.

Attempts at a phylogenetic system of classification of the Cruciferae have been frustrated by the fact that all characters of possible systematic importance vary independently of one another. However, one must assume that the most recent classification (that of Schulz published in 1936) comes nearest to being a natural one.

That being so, it would appear that all streams of evolution within the family have contained self-sterile species. Indeed we can go further, for of the 17 genera of which four or more species have been tested, only Lepidium, Aethionema, Draba and Erophila (four species according to Winge, 1940) presented only self-fertile species. Even more remarkable, only one genus, Iberis, presented only self-sterile species. But in most characters which vary within a family one expects a strong correlation between the species of a genus. Here there seems to be little positive correlation, or even a negative one. The formal explanation of this would be that there is some force acting to maintain diversity in respect of self-fertility and self-sterility 
even in small taxonomic units like genera. The nature of this force presents a major problem in plant evolution, which cannot be discussed fully here.

It does appear, however, that for the survival and evolution of a taxonomic group, a balance between outbreeding and inbreeding is an advantage. The outbreeding species would provide the store of genetic variation which had been used in the past and would be used in future as the source of new genotypes needed in new environments. The inbreeding species, arising from the outbreeding species as evoked by circumstances, would provide the genetic solutions to the problems of survival presented at the moment by divers environments, but they would continually become obsolete with the passage of time. One might say that the inbreeding species ensure the survival of the group at any instant but the outbreeding species ensure the survival of the group through time. One must point out that the inbreeding species are not of course completely self-fertilising, for, as stated earlier, they all have functioning nectaries and will therefore undergo finite, if small, amounts of cross-pollination.

That the Cruciferae present such a clear example of this variation in degree of outbreeding is probably because they have utilised in the main a single outbreeding mechanism-self-incompatibility. A classification of the family into self-fertile and self-sterile species thus gives us directly a classification into outbreeding and inbreeding species.

It may be noted in passing that other authors (e.g. Kirchner, I905, and Beddows, 1931) have observed a strong correlation between the perennial habit and self-sterility. Such a correlation is present in the Cruciferae but it is rather weak. Out of 80 self-sterile species, 34 $(42.5$ per cent.) are perennials while out of 102 self-fertiles only 26 (25.5 per cent.) are perennials. The Brassiceae, with the highest frequency of self-sterility (22 out of 35 ), contain only 5 perennials. all self-sterile.

Acknowledgments. - In addition to the numerous botanic gardens who supplied seed, I am indebted to Dr Verne Grant of the Rancho Santa Ana Botanic Garden, California, and to Mr B. T. Lowne, Hon. Sec. of the British Seed Exchange, for collections of wild seed. I am also grateful to Mr A. Gavin Brown for permission to use his radish data.

\section{SUMMARY}

The demonstration that incompatibility in Iberis amara is governed by a sporophytically controlled reaction of both pollen and style leads to a re-examination of published data on other Crucifers.

I. Published data on Cardamine pratensis, Capsella grandiflora and Brassica oleracea can all be shown to be in concordance with the Iberis results.

2. Unpublished data on Raphanus sativus and Brassica campestris are equally consistent. 
3. It is concluded that self-incompatibility throughout the Cruciferae is probably due to the same mechanism.

4. This is strengthened by the fact that incompatible pollen is inhibited before the stigma has been penetrated in all Crucifers examined for pollen growth.

5. The continued self-sterility of artificial tetraploids induced in Brassica and Raphanus is explained by sporophytic control.

A survey of 182 species, of which 80 are self-incompatible, indicates a systematic distribution of self-incompatibility. Tribes and even genera tend to contain both outbreeding and inbreeding species. This indicates that both inbreeding and outbreeding are necessary for the evolution and survival of a tribe or genus.

\section{REFERENCES}

Bateman, A. J. 1952. Self-incompatibility systems in Angiosperms. I. Theory. Heredity, 6, 285-3 I0.

bateman, A. J. 1954. Self-incompatibility systems in Angiosperms. II. Iberis amara. Heredity, 8, 305-332.

BeAtus, R. 1934. Die Selbsterilität von Cardamine pratensis. Jahrb. Wiss. Bot., 8o, 457-503.

BEDDOWs, A. R. 1931. Seed-setting and flowering in various grasses. Welsh Plant Breeding Station Ser. H. Bull. No. 12.

BöCHER, T. W. I95I. Cytological and embryological studies in the amphi-apomictic Arabis Holboellii complex. Kongelige Danske Videnskabernes. Selskab. Biol. Skr., 6 (7), I-59.

CORRENS, c. 1912. Selbsterilität und Individualstoffe. Festschr. med.-naturwiss. Ges. 84 Vers. deutsch. Naturforsch. u. Arzte, pp. 186-217.

CORRens, c. 1928. Neue Untersuchungen an selbsterilen Pflanzen. I. Tolmiea Menziesii. Biol. Zbl., 48, 759-768.

CROWE, L. K. 1954. Incompatibility in Cosmos bipinnatus. Heredity, 8, I-15.

EAST, E. M., AND MANGELSDORF, A. J. 1925. A new interpretation of the hereditary behaviour of self-sterile plants. Proc. Nat. Acad. Sci., II, I66-1 71 .

GERSTEL, D. U., AND RINER, M. E. 1950. Self-incompatibility studies in guayule. I. Pollen-tube behaviour. 7. Hered., 4I, 49-55.

HOWARD, H. W. 1942. Self-incompatibility in polyploid forms of Brassica and Raphanus. Nature, 149, 302.

HUGHes, M. B., AND BABCOCK, в. B. 1950. Self-incompatibility in Crepis fetida L. subsp. rhreadifolia. Genetics, 35, 570-588.

KAKIZAKI, y. 1930. Self- and cross-incompatibility in the common cabbage. Fap. Journ. Bot., 5, 133-208.

KIRCHNER, 0. 1905. Uber die Wirkung der Selbstbestäubung bei den Papilionaceen. Naturw. Zeitschr. Land-Forstwirtschaft, $3,97$.

LAWRENCE, W. J. C. I930. Incompatibility in polyploids. Genetica, 12, 269-296.

LEWIS, D. 1947. Competition and dominance of incompatibility alleles in diploid pollen. Heredity,, , 85-108.

LEWIS, D. 1949. Incompatibility in flowering plants. Biol. Rev., 24, 472-496.

MIzushima, U. 1950. On several artificial allopolyploids obtained in the tribe Brassiceae of Cruciferae. Tohoku 7. Agric. Res., I, 1 5-27.

ODLAND, M. L., AND NOLL, C. J. 1950. The utilisation of cross-incompatibility and self-incompatibility in the production of $\mathrm{F}_{1}$ hybrid cabbage. Proc. Am. Soc. Hort. Sci., 55, 391-402.

RILEY, H. P. I932. Self-sterility in Shepherds' purse. Genetics, 17, 231-295. 
RILEY, H. P. 1936. The genetics and physiology of self-sterility in the genus Capsella. Genetics, 21, 24-39.

schulz, O. E. 1936. “Cruciferae" in Naturliche Pfanzenfamilien, 2nd edition. (Ed. Engler and Prantl), Leipzig.

SEARS, E. R. 1937. Cytological phenomena connected with self-sterility in the flowering plants. Genetics, 22, I30-181.

STEBBINS, G. L. I95I. Natural selection and the differentiation of Angiosperm families. Evolution, 5, 299-324.

stout, A. B. I93I. Pollen tube behaviour in Brassica pekinensis with reference to self-incompatibility in fertilisation. Amer. 7. Bot., ${ }_{18} 8,686-695$.

WINGE, ø. 1940. Taxonomic and evolutionary studies in Erophila based on cytogenetic investigations. Compt. Rend. Lab. Carlsberg, 23, $4 \mathrm{I}-78$. 